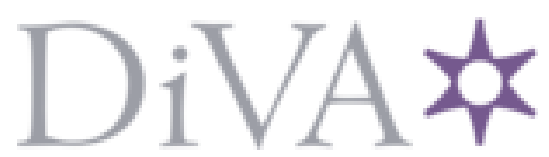

http://www.diva-portal.org

\title{
Postprint
}

This is the accepted version of a paper published in International journal of technology and design education. This paper has been peer-reviewed but does not include the final publisher proofcorrections or journal pagination.

Citation for the original published paper (version of record):

Björkholm, E. (2014)

Exploring the capability of evaluating technical solutions: a collaborative study into the primary technology classroom.

International journal of technology and design education, 24(1): 1-18

http://dx.doi.org/10.1007/s10798-013-9240-1

Access to the published version may require subscription.

N.B. When citing this work, cite the original published paper.

Permanent link to this version:

http://urn.kb.se/resolve?urn=urn:nbn:se:kth:diva-120144 
Exploring the capability of evaluating technical solutions: A collaborative study into the primary technology classroom

\section{Eva Björkholm}

KTH Royal Institute of Technology, School of Education and Communication in Engineering Science, Department of Learning

Osqars backe 31, SE-100 44 Stockholm, Sweden

e-mail: evabjork@kth.se

Telephone: +46 87909839 


\section{Abstract}

Within the field of technology education, evaluating technical solutions is considered as an important topic. Research indicates that pupils have difficulties in evaluating technical solutions in terms of fitness for purpose, i.e. how effective a technical solution supports its intended function. By using the learning study, which is an iterative and collaborative research approach, the study explores the capability to evaluate technical solutions in terms of fitness for purpose, what it takes to know it and how to best enhance its learning in the primary technology classroom. Audio and video recorded interviews, teachers' meetings and lessons are the base data for the study. A contribution of the study is the understanding of this specific knowing, and what is critical for learning and thus to an improvement of technology teaching practice.

Key words: primary technology classroom, fitness for purpose, function, learning study

\section{Introduction}

The capability to evaluate technical solutions is highlighted by several authors as an important educational outcome within technology education (Barlex 2011; Coles \& Norman 2005). It is considered essential as an analytical tool for making design decisions and for interpreting existing technological objects and systems. This capability is also advocated in technology curriculum documents across the world. According to the Swedish technology curriculum of 2011 (National Agency for Education, Sweden 2011), which forms the background for this study, the teaching of technology should include giving pupils possibilities to develop knowledge about technology in everyday life. This knowledge is described more precisely in terms of the ability to identify and analyse technical solutions based on their function, i.e. what they do, and fitness for purpose; in other words, how effectively they support their intended functions. Another example is the New Zealand technology curriculum, which highlights the evaluation of technical solutions in terms of fitness for purpose, including physical and functional aspects (Ministry of Education, New Zealand 2007).

The limited amount of empirical research done in this area of technology education indicates that evaluating the fitness for purpose of technical solutions entails certain difficulties (Compton \& Compton 2011; Oboho \& Bolton 1991). However, what one has to know in order to be able to evaluate the fitness for purpose of technical solutions is not self-evident. Developing teaching of certain target areas in systematic ways (Nuthall 2004) requires an explication of the meaning of knowing. Moreover, in order for students to develop the specific ways of knowing (Carlgren 2007) of a target area (in this case technical solutions' fitness for purpose), the teaching must be planned to make it possible for students to experience and discern what is critical for learning.

Several scholars argue that research on technology education should focus on how teachers teach, and how students learn, and the relationship between teaching and learning (Johnson \& Daugherty 2008; Jones, Buntting \& de Vries 2011; McCormick 2004; Wilson \& Harris 2003). The involvement of teachers as research partners is also highlighted (Benenson 2001; Jones et al. 2011; Merrill 2004) as one way of translating research into practice, and thereby contributing to breaking down barriers between the academic field and practice. 
The aim of this article is to explore what it means to be able to evaluate the fitness for purpose of technical solutions. Through the collaborative and iterative research approach learning study, we explore what is critical for pupils' learning about the evaluation of technical solutions and how this learning can be enhanced by teaching in the primary technology classroom.

\section{Evaluating technical solutions}

Technical objects are man-made constructions in order to perform certain functions. These functions are closely linked to human intentions and activities. Technical objects are thus physical objects on the one hand, and intentional objects on the other; they have both a 'physical nature' and a 'functional nature' (de Vries 2005; Kroes 2002). In the user context, it is mainly the object's function in relation to the realization of the goal or purpose that is in focus; how the object is put together and how it works is of minor importance. From the engineering perspective, however, emphasis lies on how to construct a physical object that realizes or performs a certain function.

In this article, I will use the word 'construction' to denote how a technical object is made in order to achieve specific functions. The philosophical concept 'physical nature' of an object or system includes "physical properties, such as size, shape, colour, weight, smell, chemical composition, etcetera" (de Vries 2005, p.18), denoting excessively extensive aspects of technical solutions. The word 'design' (as a noun) is used in the engineering and designer context in various ways, such as denoting "the style, form and other properties an object has been given" (Granath 2005, p.145), and the plans from which the object is built (Vincenti 1993). Moreover, in the technology educational context, the design takes aesthetic and marketing domains into consideration, besides the constructional, i.e. "how it is put together", and the technical domains describing "how it works" (Barlex 2007, p. 52). The word 'construction', which is used in the Swedish technology curriculum, includes these constructional and technical areas. The construction can also be understood in relation to 'structural rules', underpinning the assembly and the interaction of the components of a technical object or system (Ropohl 1997) and the 'fundamental design concepts' in the framework of Vincenti (1993); the 'operational principle', i.e. "how its characteristic parts ... fulfil their special function in combination to an overall operation which achieves the purpose" of the device (Polyani in Vincenti 1993, p. 208) and the 'normal configuration', i.e. "the general shape and arrangement that are commonly agreed to best embody the operational principle" (Vincenti 1993, p. 209). Here the word 'construction' is used to offer a more technically focused picture of technical objects and systems that will hopefully be of practical use as tools when analysing and evaluating technical solutions from this point of view in the technology classroom.

Technical objects and systems are thus designed, developed and produced to achieve specific functions. These functions can be divided into a main function, which corresponds to the primary need that the object or system must satisfy, and secondary functions, i.e. other functions that are appropriate to consider (Landqvist 2001). The functions are often described in terms of criteria that the object must meet, and the results in terms of technical solutions have several alternatives of which some fulfil the function better than others. For example, 
some materials are better suited than others for use in a particular object in order to fulfil the function. Knowledge of functions, as well as knowledge of the relationship between function and construction, thus have evaluative elements.

Although there is limited access to research on pupils' understanding of technical solutions (Frederik, Sonneveld \& de Vries 2011), results indicate that it involves certain difficulties. Two case studies by Compton \& Compton (2011) showed that the fitness for purpose and the link between constructional and functional attributes was difficult for pupils to understand, both in primary and secondary education. Oboho \& Bolton (1991) studied how 50 pupils in the 11-16-age range judged whether a designed artefact was a "good" or "bad" design. The younger pupils tended to respond more in terms of function than construction, stating what they could do with artefacts in a concrete operational way. The pupils' judgements of artefacts became increasingly oriented towards constructional terms with increasing pupil age.

Little has been written on teaching strategies for product judgment and the development of evaluative skills (McLaren 1997). Cajas (2001) highlights the need for research on how young children learn about the functional properties of materials, stating that young children have problems in distinguishing the properties of the objects from the properties of the material that made the object. A contribution to the field is a study by Chatoney (2008), observing pupils aged 6-7, and their development of knowledge about materials during activities to do with designing and making a toy. The analysis was based on the relationships between material and object, and teacher-pupil interactions. The results show that knowledge about materials has a central position in this kind of activity. The knowledge is introduced at the beginning of the activity as soon as the functions are defined, and it is viable throughout the entire process.

In summary, the capability of evaluating technical solutions concerning fitness for purpose seems to involve certain difficulties such as linking the function and construction. In order to develop teaching strategies that promote pupils' learning, it is necessary to explore the meaning of this specific knowing. The purpose of this study is to explore what it means to be able to evaluate the fitness for purpose of technical solutions within primary technology education. The study is conducted as a learning study, focusing on what is critical for pupils' learning in relation to this specific knowing, and how teaching can enhance pupils' learning. The learning study and its theoretical framework of phenomenography and variation theory will be presented in the next two sections of the paper.

\section{Learning study}

In a learning study, focus is on a particular object of learning, i.e. something which the pupils are supposed to learn, and on the related teaching-learning process as it is practiced in the classroom. The model has a collaborative approach, where a group of teachers, usually together with a researcher, try to improve teaching and learning in relation to the specific object of learning. What is critical for learning something specific is explored through a systematic and iterative process (see e.g. Marton \& Pang 2006).

According to Marton \& Pang (2006) learning study can be considered as a development of the Japanese lesson study (for an overview of lesson study see for example Fernandez, Cannon \& 
Chokshi 2003; Lewis 2000) or as a hybrid of a design experiment (e.g. Brown 1992) and a lesson study, as teachers and researchers together develop the object of learning, and the research lessons are based upon a theoretical framework of learning.

A learning study is a cyclic process of planning and revision, as shown in Fig1. Starting with choosing an object of learning, the next step is to design a pre-test. The pre-test and the following steps describe a so-called cycle carried out with a teacher and a group of pupils. The next cycle is carried out in another group of pupils and with another teacher, etc. In each cycle the lesson is analysed and evaluated in relation to the object of learning and the lesson is revised. By working iteratively on planning, evaluating and revising a lesson dealing with the object of learning, knowledge is produced about teaching and pupils' learning in relation to this content, as well as content knowledge itself.

Fig 1 . The learning study cycle

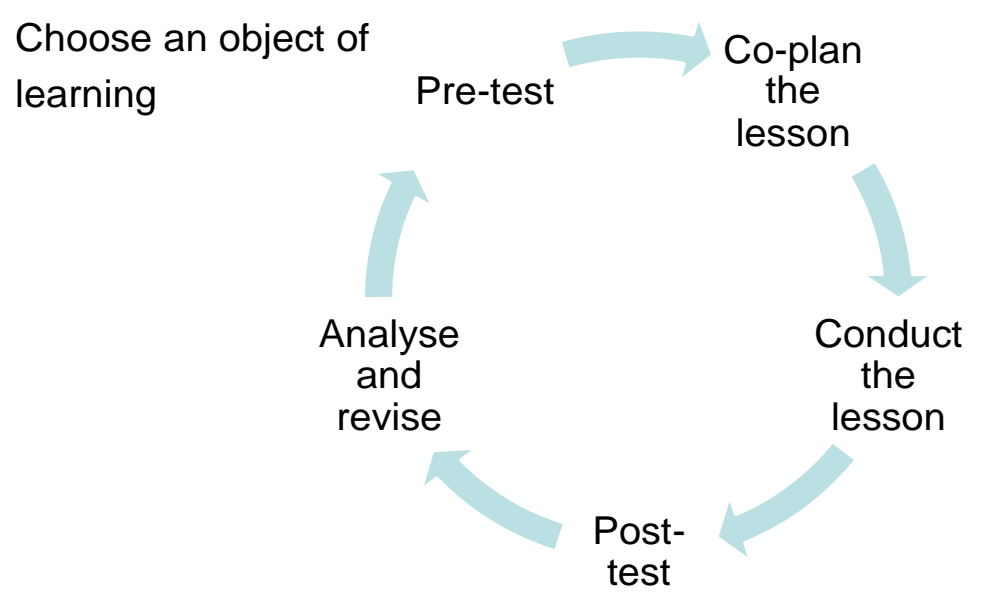

Throughout the cyclic process student knowing and learning is analysed by means of phenomenography and variation theory. This theoretical framework will be presented in the following section.

\section{Phenomenography and variation theory}

Phenomenography is a qualitative research approach (Marton 1981) grounded in a nondualistic ontological position, depicting experience as an internal relationship between the individual and the world. A basic assumption is that people perceive, understand or experience a particular phenomenon in the world in a limited number of qualitatively different ways. Some ways of experiencing something are considered more powerful than others because of differences in discernment. The result in a phenomenographic study is an outcome space of categories describing the qualitatively different ways of experiencing the phenomenon. These categories are logically related to each other and usually formed as a hierarchical structure of increasing complexity.

A certain way of experiencing something, i.e. a way of seeing, understanding or apprehending something, is a way of being aware of it. Awareness can be characterized in terms of a differentiated figure-ground structure (Marton \& Booth 1997). This means that some aspects are in the foreground; they are explicit and thematized, while other aspects are in the 
background, being implicit and unthematized. Experiencing something in a certain way can be characterized by its referential and structural aspects (Marton \& Booth 1997; Marton \& Pong 2005). The referential aspect represents the particular meaning of the object, while the structural aspect of the experience is the way of delimiting the object from and relating it to a context (the "external horizon"), and delimiting component parts of the object and relating them to each other and to the whole (the "internal horizon"). The referential and structural aspects are mutually intertwined; a change in the structural aspect of the experience corresponds to a change in its referential aspect.

A particular way of experiencing something can be understood in terms of discerned aspects, and the relations between them that are simultaneously present in the focal awareness (Marton $\&$ Booth 1997). These aspects correspond to dimensions of variation, i.e. the things we observe in a specific situation we tacitly experience as values in these dimensions. Variation in the experienced aspects can be used to describe any particular way of experiencing a phenomenon, as well as the differences between ways of experiencing something (Pang 2003). The link between phenomenography and its further development, the variation theory, can be seen by focusing on the structural aspect of a conception (Marton \& Pong 2005; Pang 2003).

According to variation theory, learning is seen as a change in the learners' ability to discern certain aspects of the phenomenon (Marton \& Tsui 2004). From this follows that, in order to make learning possible, these aspects must be made possible to discern. In order to discern them, one must experience these aspects as dimensions of variation, i.e. a difference in the value of the aspect. For example, one would not be able to discern the aspect of gender if there were only one gender in the world (Pang 2003). The aspects are named 'critical aspects' as long as the learner does not discern the aspects that must be discerned in order to master the object of learning. The critical aspects are thus related to the specific object of learning, and to the pupils' experiences of the object of learning. Consequently, the aspects that are critical for pupils' learning must, at least partially, be found empirically.

\section{Methodology - A learning study concerning evaluation of technical solutions}

\section{The learning study setting}

Primary technology education in Sweden is part of the national technology curriculum for compulsory school (National Agency for Education, Sweden 2011). In contrast to the former curriculum document of 1994, this new curriculum describes particular core content of technology education, specified for grades 1-3, 4-6 and 7-9. In primary education, the subject of technology is often taught by general primary school teachers, who have the responsibility for the teaching of all subjects except for music, sloyd $^{1}$ and physical education.

The learning study reported here was conducted in collaboration with a group of four teachers in a Swedish public primary school over a period of six months. The teachers' levels of

\footnotetext{
${ }^{1}$ Sloyd is a compulsory subject in the Swedish school system, aiming to develop the ability to design and create self-made products in textile, wood and metal.
} 
experience of working as a teacher ranged from 3 to 35 years. All teachers had some experience of technology teaching, varying from a few lessons within a fixed national technology program to conducting their own comprehensive technology projects each semester for several years. The extent of teachers' training in technology education ranged from none at all to studies corresponding to one term full-time study. Two classes in grades 1 and 2 (pupils aged 7-8 years) participated in the study. There were 23 pupils (grade 1) and 26 pupils (grade 2) in the participating classes. None of the classes had experienced any previous explicit technology teaching during their schooling.

Participation in the study was voluntary and informed. Since underage students were involved, their guardians' informed consent was acquired. Specific attention was paid to data collection by video recording related to participants. Data related to participants has been treated with anonymity and confidentiality, which means that all names involved have been made anonymous in the transcription and in all subsequent handling of the research material.

Possible objects of learning were discussed during an initial teacher-researcher meeting. Based on one of the teachers' experiences regarding pupils' difficulties in evaluating their own solutions within problem-solving activities, the teacher-researcher group agreed to choose the object of learning "to evaluate technical solutions in terms of fitness for purpose". In order to further delimit the object of learning, the opening-closing function was selected. In discussing the pupils' presumed understanding of this content, one of the teachers brought up the idea of needing a handle to open a door or a window. Taking this idea into consideration and having a desire to find as many ways of experiencing this specific content as possible, we designed the pre-test.

\section{The pre-test}

The pre-test was carried out in the form of interviews with all pupils in pairs, except for two pupils who were interviewed individually. Pairwise interviews were chosen because of the young pupils' age, the intention being to create a confident and enjoyable interview situation, and in that way obtain richer empiric material. The semi-structured interviews were conducted during school time in a separate room close to the classroom, and lasted for about 10 minutes. During the interviews, some everyday objects representing a variation of technical solutions for opening/closing were discussed, such as zippers of different sizes and models, juice bottles with screw caps, a matchbox, hinges of different types and sizes, and a tube for storage of aspirin. The objects were placed on the table in front of the pupils and they were encouraged to investigate the different opening and closing devices. In addition, a picture of an opened window was discussed in order to further illustrate the relation between hinges and their function. The interview questions focused on the evaluation of the objects' opening and closing function in terms of fitness for purpose. The pupils were asked to evaluate the technical solutions and to argue to support their views.

The interviews with pupils in grade 1 were designed in a slightly different way to the initial interviews in grade 2, based on the analysis of the first interviews. These minor changes of the questions were made to focus more clearly on the physical aspects of the technical solutions. 
In this way the entire interview material became richer, since the phenomenon was highlighted from several perspectives.

The interview questions to the pupils included, but were not restricted to:

- Why does one open and close things in these ways?

- Is there anything not so good with this way of opening and closing?

- What things could be opened and closed with this device? Why? Are there any things that are not appropriate to use this device on?

- How does the opening/closing device function?

\section{The research lessons}

The analysis of the pre-test resulted in qualitatively different categories of experiencing the fitness for purpose of technical solutions concerning opening-closing, and based on the difference between these categories, critical aspects were identified. These critical aspects formed the starting point when planning the lessons. The variation theory was used as a tool when planning, opening up dimensions of variation, in order to make the intended learning possible. This means that the lesson design focused on certain features such as the variations among users and materials etc. All lessons included a classroom discussion and a problemsolving task given to pupil pairs. In order to focus on the significance of the construction for fulfilling the function, different kinds of technical solutions having an opening/closing function, such as zippers, hinges, and screw caps, were compared and examined during the lessons. Different types of materials, such as plastic, metal, wood, fabric, glass and cardboard, and their areas of use and properties were also emphasized in the first two lessons. Materials were chosen since this was the primary feature mentioned by pupils' when talking about aspects of the construction in the pre-test, and thus they could be considered as an appropriate link between the user and constructor contexts. Different types of technical solutions with opening and closing functions of bottles and boxes were examined in terms of aspects of the construction. Key components of a bottle's screw cap mechanism were discussed, and hinges of different types of objects and of different materials were compared. The orientation of pupils' problem-solving task changed through the study from designing and making objects from the perspective of different types of users and their needs and situations, to taking the starting point from the pupils' own experience and familiar situations. In concrete terms, in the last two lessons pupils designed and made appropriate opening-closing solutions for boxes and bottles intended for a picnic. Thus, secondary functions such as preventing leakage, durability, and easy handling varied and were related to different possible technical solutions. Each lesson took place in half a class (11-13 pupils) with one of the participating teachers.

After the lesson had been conducted, it was preliminarily analysed by the researcher, and not by the teachers and researcher together, due to time constraints. At the subsequent teachersresearcher meeting, the analysis was discussed, and based on this discussion changes in the lesson design were proposed. Thereafter, three additional cycles of lesson planning, teaching and revising the lesson were conducted. 


\section{Data generation and analysis}

Data was generated by audio recording of a total of six teacher-researcher sessions, each of which was approximately two hours long. All pre-test interviews were documented by audio and video recording separately. Each of the four lessons was audio-recorded and videorecorded by two separate video cameras, and lasted for approximately 60 minutes. Texts, drawings and models produced by pupils during the lessons were collected or documented photographically.

All generated data was transcribed, and in addition to verbal communication bodily expressions were documented. The interview material was analysed using phenomenographic analysis, which focused on pupils' ways of experiencing or understanding the phenomenon 'the fitness for purpose of technical solutions'. The different ways of experiencing the phenomenon became visible by reading the data material many times. The analysis of the pretest resulted in four qualitatively different categories, each describing a particular way of experiencing the fitness for purpose of technical solutions. The different ways of experiencing the phenomenon were analysed in terms of structural aspects, focusing on the aspects of the phenomenon that were brought to the forefront of attention. The differences between the structural aspects discerned were understood in terms of critical aspects and dimensions of variation (cf. Pang 2003), i.e. these aspects were critical for pupils to discern in order to develop a more complex understanding. The discerned aspects of the phenomenon were thus seen as corresponding to a particular way of experiencing the phenomenon as well as for differences between ways of experiencing the phenomenon. This way of characterizing 'experiencing' indicates a new orientation in phenomenography, according to Pang (2003) and Runesson (2006).

The lessons were analysed using variation theory as an analytical tool. The analysis of the lessons focused on identifying aspects that were critical for pupils' learning and how the pupils came to discern these aspects of the object of learning opened up in the learning situation.

\section{Findings}

This article describes a study aiming to investigate what it means to be able to evaluate technical solutions concerning opening-closing in terms of fitness for purpose. Here I present the aspects that were identified and how these emerged during the research process in relation to pupils' understandings of the phenomenon. First, I describe which qualitatively different categories emerged from the analysis of the pre-test and the critical aspects identified. Then, through an analysis of the conducted research lessons, I show how additional aspects critical for learning appeared.

\section{Pre-test}

Through the phenomenographic analysis of the pre-test, four qualitatively different categories emerged for describing pupils' experience of technical solutions' fitness for purpose. These were: (a) effectiveness for me, (b) effectiveness for others, (c) construction dependency, and (d) technical efficiency. The categories are logically related to each other in that the lower levels are included in the higher levels, of which category (a) is the least complex level, 
describing the less developed way of experiencing. The four categories describe ways of experiencing the fitness for purpose of technical solutions. They are discussed in more detail below.

\section{A. Effectiveness for me}

In this category, focus is on the subject's own use of different technical solutions. A technical solution that achieves a particular desired function well is appropriate. The appropriateness is usually linked to different functions that make everyday life easier. Besides the main function opening-closing, other functions such as handling, storage and aesthetic aspects are considered.

Interviewer: Is there anything not so good with opening the matchbox in that way?

Eric: Not really /../ it is great, it is very easy to open.

Anna: And very easy to close.

In focusing on one's own use, the technical solution is taken for granted. The pupils do not reflect on any aspects of the object's construction. This type of understanding was very common among pupils. In the next example, Steve tries to open a tube designed for storage of aspirin.

Interviewer: What do you think of opening and closing the tube? You will get to examine how you open and close it.

Steve: Eehuu (tries to pull the cork out of the tube) it's very hard.

Interviewer: Is there anything that is good about opening and closing like that?

Steve: It's bad, it's just bad /../ Because one must use the teeth with this (takes the tube from the pupil Ella) Aahm aahm (grabs the cork with the fingers and then uses his teeth).

Here we see that the understanding relates to implicit previous experiences of opening things in an easier way.

B. Effectiveness for others

In this category, pupils distinguish a technical solution's purpose that is more extensive and complex. The purpose could, for example, be related to different types of users who have specific needs. Young children, the elderly, sick and weak people represent different categories of users with specific needs, requiring different specific functions.

Interviewer: Is it a good or a bad way to open and close it like that?

Agnes: It's actually quite bad for some, some people may not be so strong so they can't manage to remove it /.../ and it becomes pretty tough for them.

\section{l../}

Interviewer: Could it be good in some way that it is a bit hard to open, then? 
Agnes: Mm yeah, but yet no. 'Yes', (with emphasis) because then perhaps no one can steal or something if you have kids, and they're like child-safe you could say. And it's 'no' just because some people may not even be able open them and then one has to...

Interviewer: Which people do you mean; are you thinking of adults, or what?

Agnes: Yes.

Interviewer: What adults may have difficulties opening one of those, then?

Agnes: Aah, it could be my mum (laughs), she is quite weak.

In the excerpt above, Agnes discerns different users by comparing users such as young children and weak people whose needs and situations are related to different functions.

C. Construction dependency

The fitness for purpose is based on one or several aspects of the objects' construction, such as material, form and components, and how they help to realize the function. For example, an opening and closing device for a liquid has to prevent leakage, which poses special constructional requirements. One or several of these aspects are seen as crucial to fulfil the desired function. The technical solution is often illustrated by showing a bodily movement, e.g. a screwing or a lifting gesture, or by naming the activity such as 'screwing', 'lifting' or 'pushing'. This is exemplified in the following excerpt.

Interviewer: If you think of the designers of these things, why did they decide to open and close the things in this way?

Sarah: Perhaps because it won't escape and perhaps because what is in there should not fall out /.../ because it has plastic, there is a cap, one screws it.

Interviewer: One screws it and then it won't escape?

Sarah: No.

Interviewer: How does such a cap work?

Sarah: Mm, what did you say?

Interviewer: How does that cap work so that the juice won't escape?

Sarah: You screw it.

In the following example we discuss how to open and close a bottle with a screw cap and a matchbox.

David: That one you open like that (pointing to the bottle) because it gets very tight so /.../ Eh, up here it will be tight so you, because if it falls over, the liquid shouldn't escape.

Sam: It will if you pour water into this (holding the matchbox), then this would be wet. If you had a box made of plastic it would still escape in tiny, tiny amounts.

David: It would even escape here (pointing to the gap between the drawer and the box).

Interviewer: Why would it escape from that? 
David: Because of the type of material.

Sam: It is so easy to press out (pushes the drawer out of the box).

David: It is not tight, it is made of a material that is not waterproof.

Sam: Which is cardboard.

David: It would run straight through like this (showing with hands).

In the extract above David first discerns the functions opening/closing and prevention of leakage. Sam then describes how the form contributes to fulfil the function of preventing leakage and relates to different materials. When talking about plastic and cardboard they also relate to the functional properties of the different materials.

D. Technical efficiency

In this category, different common technical solutions are identified and compared in terms of how efficiently they realize specific functions. In the following example different solutions for opening and closing a bottle is discussed.

Interviewer: The opening device of the bottle, is there anything that is not good?

Josephine: Mm, sometimes it's a bit hard to open.

Robert: Yes when it's new so it is (inaudible) (pause) or rather, I think you can have just as a lid and open like this (shows with hands) it would be a bit easier.

Interviewer: Are there such bottles?

Robert: No I don't think so actually.

Josephine: But there are water bottles that have a small lid.

Robert: Yes I think there are, and then you just lift it (lifts the screw cap) and then you drink.

Interviewer: If you close that one you have to screw it like that, yes.

Josephine: Yes and then one has to screw very tightly so that everything doesn't escape.

Robert: Otherwise, you just do like this (demonstrates with a lifting movement).

In this excerpt Josephine first identifies the problem of opening bottles, and Robert suggests a different solution than the screw cap, a hinged lid. Josephine then proposes another solution, a different type of lid, and the pupils discuss this lid that you remove by lifting. Common technical solutions such as screws and hinges are thus identified in different types of bottles.

Extracts in this category indicate a more complex understanding of key components and how they interact to realize the function. The technical solution is identified, although it may appear in different ways, for example, different sizes and materials. In the extract below, Tom investigates different types of hinges. 
Tom: This is a very big hinge (takes the biggest hinge) to a door, this is a size for doors, I think /.../ because it's very big /.../ this is a bit smaller (takes one of the smaller hinges) it's for smaller things, a small window perhaps or something like that /.../ You can use it for very small things that you can build, it suits almost to such a video camera (pointing to the camera) /.../ this is very small /.../ this is very small for you see, the thing you look at, you know that picture, the screen, that one you can swing out, and it is about this small, it's another kind of hinge.

The pupil Tom discerns the hinge in the video camera and can make comparisons with hinges in other types of objects, like windows and doors.

\section{Critical aspects identified}

The analysis of the interviews resulted in four qualitatively different ways of experiencing the fitness for purpose of technical solutions, as outlined in the previous section. The categories of descriptions reflect the differences in structure and organization of awareness. Certain aspects are in the foreground of attention, and are thus discerned. In order to be able to discern a certain aspect, one has to experience it as a dimension of variation. This reasoning will be elaborated on further in the text below, describing the categories and their structural aspects. The analysis of the categories' structural aspects is summarized in Table 1.

In category A, the focus of attention is on pupils' using and the fulfilling their own desired functions, exclusively. In addition to the main function of opening/closing, pupils discern a variation of functions, such as easy handling, durability and storage, and relate these to the fitness for purpose. In order to evaluate the fitness for purpose of the technical solution, it is critical to identify the main intended function, in this case the opening and closing. The fulfilling of additional functions familiar to pupils and based on their own use is also critical when evaluating the corresponding fitness for purpose. The aspects of functions and needs are dimensions of variation, and are necessary to discern in order to experience the phenomenon in the way described in category A.

In category $\mathrm{B}$, the attention is on using, but with reference to a broader context of users. A variety of users and their specific needs and the related functional requirements are taken into consideration when evaluating the fitness for purpose. The aspects of user and functional requirements are dimensions of variation and thus aspects that are necessary to discern in order to experience the fitness for purpose in the way described in category B.

Category $\mathrm{C}$ describes an understanding of fitness for purpose as technical efficiency, with the focus on various aspects of the construction, i.e. the physical attributes. The aspects discerned are different materials, forms and components in relation to the functional requirements.

Finally, for category D, the attention is on the complete technical solution, including the interaction between key components. Different common technical solutions are compared and evaluated in terms of fitness for purpose. The aspect of technical solution in relation to functional requirements is a dimension of variation and thus considered as an aspect necessary to discern. 
Table 1. Analysis of the categories in terms of structural aspects.

\begin{tabular}{|l|l|}
\hline $\begin{array}{l}\text { Category } \\
\text { Technical solutions' fitness for purpose as: }\end{array}$ & Structural aspects \\
\hline $\begin{array}{l}\text { (A) effectiveness for me } \\
\text { based on own needs and situation are fulfilled }\end{array}$ & Own needs and related functions \\
\hline $\begin{array}{l}\text { (B) effectiveness for others } \\
\text { Fitness for purpose is about fulfilling functions } \\
\text { based on others' needs and situations }\end{array}$ & $\begin{array}{l}\text { Specific needs or situations of others and } \\
\text { related functions }\end{array}$ \\
\hline $\begin{array}{l}\text { (C) construction dependency } \\
\text { Fitness for purpose is based on how efficiently } \\
\text { aspects of the construction help to realize the } \\
\text { function }\end{array}$ & $\begin{array}{l}\text { Material, form or components linked to } \\
\text { functional requirements }\end{array}$ \\
\hline $\begin{array}{l}\text { (D) technical efficiency } \\
\text { Fitness for purpose is based on how efficiently } \\
\text { commonly agreed technical solutions realize } \\
\text { the function }\end{array}$ & $\begin{array}{l}\text { Common technical solutions and the } \\
\text { interaction between key components of the } \\
\text { construction linked to functional requirements }\end{array}$ \\
\hline
\end{tabular}

The differences between structural aspects of the different ways of experiencing the phenomenon can be considered as critical aspects necessary to discern in order to reach a more complex understanding. Consequently the critical aspects can be summarised in the following way: (1) specific needs or situations and related functions, (2) material, form or components linked to functional requirements, and (3) common technical solutions and the interaction between key components of the construction linked to functional requirements.

\section{Research lessons}

Through the analysis of the lessons, two additional aspects were identified that were critical for pupils' learning. These aspects have emerged empirically from the teaching learning process based on how pupils' experiencing of the object of learning was articulated in the classroom. These aspects were not identified in the pre-test, but through a systematic inquiry the researcher-teacher group successively became aware of aspects assumed necessary for pupils to discern in order to learn what was aimed at. Thus, the teacher-researcher group's collective understanding of the meaning of the object of learning was gradually developed. The analysis of the lessons suggests the following additional aspects: (1) materials separated from objects, and (2) main function and secondary functions related to corresponding key components. These 'new' aspects are linked to the initial four aspects in the way that they concern materials, key components and functions, and can be seen as complementary to these.

1.Materials separated from objects 
The first two lessons partly focused on different types of materials, and their areas of use and properties. This content was chosen since the researcher-teacher team considered it an appropriate link between the user and engineering context. The classroom discussion aimed to illustrate how different materials and their functional properties contribute to fulfilling the function and the fitness for purpose of technical solutions. In the following excerpt, the class talks about the material glass.

Teacher: /.../ Do we have glass left, or ...? What can you make with glass, then? Susan.

Susan: It can be for windows.

Teacher: Windows, yes. More things made of glass? Felicia.

Felicia: Car windows.

Teacher: Good. Helen.

Helen: Glass tables.

Teacher: Tables made of glass, hm, yes.

Philip: Jars.

Teacher: Lots of jars, here we have one, for example (points to the jar on the table). Sarah.

Sarah: Glass, glass (emphasizes strongly and raises her body) (short pause), and what is it called, vases.

Teacher: Yes, also the thing that is called a glass. It is usually made of glass, and there is glass that you drink out of.

The discussion gives the pupils opportunities to discern a variety of objects made of glass, for example car windows and jars. When Sarah is mentioning glass, it looks like she comes up with something according to her bodily expression and verbal accentuation that contributes to the discussion. She comes to discern the different meanings of the concept of glass, both as an object and as a material. The teacher then responds to Sarah by clarifying the aspect of varied meanings, and in that way she opens up the class to discerning the variation of meanings of glass.

In the next example, the class talks about the material cardboard, and the learning situation is opened up to discerning aspects related to objects, materials and functional properties.

Teacher: /.../ Cardboard, what can you use it for then? Erika?

Erika: If you want to send big things to someone, you can pack it, so it won't break.

Teacher: Smart. Jens, what do you think?

Jens: Pizza, pizza boxes.

Teacher: Oh yes, to put the pizza in, when bringing it home.

Ralf: You mean packaging. 
Teacher: Packaging, you think. Yes, yes. Mike?

Mike: Shoe boxes, all kinds of boxes.

Ralf: Then it is still packaging.

Teacher: Yeah, right. Oscar?

Oscar: You can have boxes, boxes, simply. Moving boxes, they are usually made of cardboard. If they are made of wood, then they are very difficult to handle and they can be prickly and hard and a lot heavier than cardboard, but anyway cardboard is strong enough to put heavy things in.

Teacher: It is good to use cardboard, a different material, you think.

Nina: There are boxes in here.

Teacher: Oh well, have you seen any?

Nina: Over there (pointing).

Teacher: Yes, we use a lot of cardboard boxes over there. Yeah, you know, talking about boxes /.../

In this excerpt, the pupils express different understandings of cardboard. The initial part of the discussion is about cardboard as different types of boxes; however, as the classroom discussion proceeds, the teacher gives the pupils the opportunity to discern a variation of possible meanings of cardboard. The comments by the pupil Ralf give pupils opportunities to experience the varying appearances of 'packaging'. Additionally, Oscar contributes to the collective knowledge production in the class through his comment on the appropriateness of different materials from the user's view, based on the functional properties of the materials, when comparing boxes made of wood and cardboard.

Discerning the material as separate from objects made of the material can be considered critical for the understanding of a material's significance, for realizing a function, and for judging the fitness for purpose of a technical solution. Moreover, discerning the specific material and its properties is necessary for this understanding. The aspect of the variation of meanings of materials, in this case glass and cardboard, seems to be critical for at least some of the pupils in this study. Thus, the aspect 'materials separated from objects' is identified as a critical aspect.

2. Main and secondary functions related to corresponding key components

During the lessons, different opening and closing devices related to different types of objects were discussed and investigated. In the following example a glass jar with a hinged lid is discussed.

Teacher: What is it that makes this possible to open and close (opens and closes a jar with a hinged lid)? Is it this thing (the locking mechanism)? Or is it (opens it with the hinge)? What do you say, Molly? You don't know? 
Molly: It is perhaps this thing that fits into the hole (pointing to the rubber ring around the jar opening).

Ellen: But it is just to, to prevent the glass, if you happen to drop it.

Marcus: Or to make it tight.

Teacher: Aha.

Marcus: It is a weird hinge.

Richard: Yes, exactly /.../

Teacher: It is some kind of hinge, some of you think.

August: Hooks!

Teacher: That doesn't look like anything we have seen before.

August: Hooks, hooks, they are hooks.

Teacher: Like hooks, see? Exactly, and this, what does it do, then (shows the locking mechanism)?

Molly: It closes the jar.

Marcus: It locks.

Teacher: It perhaps locks the jar. It opens and closes like this (shows how the lid opens and closes with the hinge). And this one locks (shows the locking device). OK.

Different parts of the jar and their functions are examined through the collective discussion. The pupils talk about the closing and locking functions and their corresponding parts of the construction in different ways. In this context, the opening-closing function is considered as the main function, and the locking-unlocking function as a secondary function. To separate the locking from the closing function, the teacher focuses on the parts linked to the different functions. The pupil Marcus is distinguishing between the closing and locking functions, and the teacher responds by showing the different parts and their corresponding functions. The pupils thus have opportunities to simultaneously discern the closing and locking function linked to different parts of the jar. In the discussion, additional parts of the jar are examined and more functions come up. Alternative functions of the rubber ring around the jar opening are mentioned, such as protection and tightening. A further dimension of the physical aspect linked to the opening and closing functions is highlighted in the example. The pupils talk about weird hinges looking like hooks. The pupils are given the opportunity to discern a hinge, a common technical solution used for opening and closing, and compare it to other hinges they have seen before. In this way, they may get the opportunity to experience an additional variation of types of hinges.

In order to evaluate the fitness for purpose of technical solutions, it is necessary to distinguish between main and secondary functions and to relate these to the corresponding key components. These aspects seemed to be critical for some of the pupils' understanding of the fitness for purpose of technical solutions. 
The critical aspects found from the pre-test and additional aspects identified in the research lessons summarize how far the teacher-researcher group's collective understanding of the meaning of the object of learning was developed. It is important to consider that the critical aspects identified in the pre-test are based on the analysis of interviews and the entire group of the pupils. In contrast, the additional aspects considered as necessary to discern emerged from classroom discussions with a smaller group of pupils in a specific learning situation. However, these additional aspects could be considered as a complement to the initially identified critical aspects, and in that way, as a contribution to the understanding of the meaning of the object of learning.

\section{Discussion}

In this study some critical aspects of the object of learning to evaluate the fitness for purpose of technical solutions for opening and closing were identified through the learning study process. These aspects are considered necessary to discern in order to develop this specific knowing. By identifying these aspects, the teacher-researcher group's collective understanding of the meaning of the object of learning was developed and specified.

The findings show the variety and increasing complexity of young pupils' experience of the fitness for purpose of technical solutions, from focusing on the user's perspective and their own use related to familiar functions, to taking the engineering perspective by considering a common technical solution with its interacting components in relation to functional requirements. The identified critical aspects of the object of learning describe what pupils must discern in order to be able to evaluate technical solutions in more complex ways. These aspects are in line with pupils' difficulties concerning the linking function and construction reported by Compton \& Compton (2011) and Oboho \& Bolton (1991), but the critical aspects identified in this study offer a more detailed and complex understanding of this specific knowing and what it takes to learn it. I argue that the words 'construction' and 'function' are powerful, directing the focus onto the main aspects, when analysing a technical object or system, and thus offer general basic concepts for the technology education context.

The critical aspect of the role of materials in fulfilling the functional requirements was not elaborated enough when analysing the pre-test. Through the iterative design of the study, opportunities arose for further elaboration of this aspect. In this way, an additional aspect emerged, concerning materials as distinct from objects. This aspect could be understood in relation to Cajas' (2001) findings concerning young pupils' distinguishing between properties of materials and properties of objects. In a similar way, the aspect of main and secondary functions related to corresponding key components emerged, contributing to the collective knowledge developed by the group of researcher and teachers.

I have seen that teachers and pupils together construct what it is possible to experience during lessons. A variation of answers and examples mentioned by the teacher and pupils could lead to a deeper and more complex understanding of what is to be learned. However, even if it is made possible for a critical aspect to be experienced in a lesson, that does not imply that all pupils learn. The collective discussions thus seem to be vital in making 7-8 year-old pupils aware of materials and functions and how to evaluate technical solutions. Giving pupils 
opportunities to experience the critical aspects through discussions allows them to explore technical solutions in terms of materials, components, and main and secondary functions from the engineering viewpoint as well as from the user perspective. Compton \& Compton (2011) suggest the content needs to be introduced across more than one level and broken down into smaller ideas, in order to enable pupils to learn about the fitness for purpose of different technical solutions. An alternative way of interpreting pupils' understandings and how to enable learning is in terms of the critical aspects that must be discerned, and to systematically design teaching that gives pupils opportunities to experience variation through classroom discussions and design activities that are linked to pupils' real problems and needs.

Previous research has discussed how results from a learning study can be of use for other teachers and contribute to the collective knowledge base of the teaching profession. Carlgren (2012) suggests that it may be fruitful to find forms for theoretical descriptions that are disconnected from the cases, e.g. as theoretical elaboration of the object of learning or descriptions of teaching-learning units within specific subject areas. Runesson \& Gustafsson (2010) have shown that it is possible for teachers who have not participated in the original learning study to use the critical aspects in new learning studies. Learning study aims to have implications for teachers and teaching, which Nuthall (2004) refers to as pragmatic validity. Eisner (1998) and Larsson (2009) suggest a variant of generalization in qualitative research, based on the perspective of the user of the research. Thus, communicated patterns produced by research can be recognized in new cases, and in that way the users of research obtain tools to identify patterns in the everyday world. By applying this kind of reasoning, the findings from this study can be used by teachers in their own teaching context by helping them identify critical aspects that they can then use for structuring the content of teaching in order to support pupils in experiencing technical solutions in more complex ways. The critical aspects identified in this study, will they be apparent in a different teaching and learning context? This is a question for further research that will contribute to a deeper understanding of the meaning of the capability to evaluate the fitness for purpose of technical solutions.

\section{References}

Barlex, D. (2007). Assessing capability in design and technology: The case for a minimally invasive approach. Design and technology: An International Journal, 12(2), 49-56.

Barlex, D. (2011). Dear minister, this is why design and technology is a very important subject in the school curriculum. Design and Technology Education: An International Journal, 16(3), 9-18.

Benenson, G. (2001). Teachers researching, children designing. Journal of Technology Education, 12(2), 56-68.

Brown, A. L. (1992). Design experiments: Theoretical and methodological challenges in creating complex interventions in classroom settings. The Journal of the Learning Sciences, 2(2), 141-178.

Cajas, F. (2001). The Science/Technology Interaction: Implications for Science Literacy. Journal of Research in Science Teaching, 38(7), 715-729.

Carlgren, I. (2007) The content of schooling - from knowledge and subject matter to knowledge formation and subject specific ways of knowing. In E. Forsberg (Ed.), Curriculum 
Theory Revisited (pp. 81-96). Studies in Educational Policy and Educational Philosophy: Research Reports 2007:10. Uppsala University.

Carlgren, I. (2012) The Learning Study as an approach for 'clinical' subject matter didactic research. International Journal for Lesson and Learning Studies, 1(2), 126-139.

Chatoney, M. (2008). Contemplation and use of technical aids in primary schools. In J. Ginestié (Ed.), The cultural transmission of artefacts, skills and knowledge: Eleven studies in technology education in France (pp. 125-147). Rotterdam: Sense Publishers.

Coles, R. \& Norman, E. (2005). An exploration of the role values plays in design decisionmaking. International Journal of Technology and Design Education, 15(5), 155-171.

Compton, V. \& Compton, A. (2011). Teaching the nature of technology: Determining and supporting student learning of the philosophy of technology. International Journal of Technology and Design education. http://www04.sub.su.se:2112/ content/k0v57q33r8562g75/fulltext.pdf. Accessed 7 September 2012.

de Vries, M. J. (2005). Teaching about technology: An introduction to the philosophy of technology for non-philosophers. Dordrecht: Springer.

Eisner, E. W. (1998). The enlightened eye: Qualitative inquiry and the enhancement of educational practice. Upper Saddle River, NJ: Prentice-Hall.

Fernandez, C., Cannon, J. \& Chokshi, S. (2003). A US-Japan lesson study collaboration reveals critical lenses for examining practice. Teaching and Teacher Education, 19, 171-185.

Frederik, I., Sonneveld, W. \& de Vries, M. J. (2011). Teaching and learning the nature of technical artifacts. International Journal of Technology and Design Education, 21(3), 277290.

Granath, J. Å. (2005). Learning in technology: A design theoretical approach to architecture education. In: L. Lindström (Ed.) Technology education in new perspectives: Research, assessment and curriculum development (pp. 144-160). Stockholm Library of Curriculum Studies 14. Stockholm: Stockholm Institute of Education Press.

Johnson, S. D. \& Daugherty, J. (2008). Quality and characteristics of recent research in technology education. Journal of Technology Education, 20(1), 16-31.

Jones, A., Buntting, C. \& de Vries, M. J. (2011). The developing field of technology education: a review to look forward. International Journal of Technology and Design Education. http://www04.sub.su.se:2112/content/m0011512152471n1/fulltext.pdf. Accessed 7 September 2012.

Kroes, P. (2002). Design methodology and the nature of the technical artefacts. Design Studies, 23(3), 287-302.

Landqvist, J. (2001). Vilda idéer och djuplodande analys: Om designmetodikens grunder. [Wild ideas and in-depth analysis: About the basis for design methodology]. Institutionen för Industridesign, Konstfack (National College of Art Craft and Design). Stockholm: Carlsson Bokförlag.

Larsson, S. (2009). A pluralist view of generalization in qualitative studies. International Journal of Research \& Method in Education, 32(1), 25-38. 
Lewis, C. (2000). Lesson study: The core of Japanese professional development. Paper presented at the Annual Meeting of the American Educational Research Association, New Orleans, LA, April, 24-28.

McCormick, R. (2004). Issues of Learning and Knowledge in Technology Education. International Journal of Technology \& Design Education, 14(1), 21-44.

McLaren, S. V. (1997). Value judgments: Evaluating design. A Scottish perspective on a global issue. International Journal of Technology and Design Education, 7(3) 259-278.

Marton, F. (1981). Phenomenography - Describing conceptions of the world around us. Instructional Science, 10, 177-200.

Marton, F. \& Booth, S. (1997). Learning and awareness. Mahwah, NJ: Lawrence Erlbaum Associates.

Marton, F. \& Pang, M. F. (2006). On some necessary conditions of learning. The Journal of the Learning Sciences, 15(2), 193-220.

Marton, F. \& Pong, W.Y. (2005). On the unit of description in phenomenography. Higher Education Research \& Development, 24(4), 335-348.

Marton, F. \& Tsui, A. B. (Eds.) (2004). Classroom discourse and the space of learning. Mahwah, NJ: Erlbaum.

Merrill, C. (2004). Action research and technology education. The Technology Teacher, 63(8), 6-8.

Ministry of Education, New Zealand. (2007). Technology Curriculum Support. http://www.techlink.org.nz/ curriculum-support. Accessed 7 September 2012.

National Agency for Education, Sweden (2011). Curriculum for the compulsory school, preschool class and the leisure-time centre 2011.

http://www.skolverket.se/publikationer?id=2687. Accessed 7 September 2012.

Nuthall, G. (2004). Relating classroom teaching to student learning: A critical analysis of why research has failed to bridge the theory-practice gap. Harvard Educational Review, 74(3), 273-306.

Oboho, E. O. \& Bolton, N. (1991). Matching students' technological thinking with the demands of a technological curriculum. International Journal of Technology and Design Education, 4(2), 54-61.

Pang, M. F. (2003). Two faces of variation: On continuity in the phenomenographic movement. Scandinavian Journal of Educational Research, 47(2), 145-156.

Runesson, U. (2006). What is possible to learn? On variation as a necessary condition for learning. Scandinavian Journal of Educational Research, 50(4), 397-410.

Ropohl, G. (1997). Knowledge types in technology. International Journal of Technology and Design Education, 7(1-2), 65-72. 
Runesson, U. \& Gustafsson, G. (2010). Learning study - knowledge production for teachers? Paper presented at the World Association of Lesson Studies International Conference, Brunei, Darusalam, 9-10 December.

Wilson, V. \& Harris, M. (2003). Designing the best: A review of effective teaching and learning of design and technology. International Journal of Technology and Design Education, 13(3), 223-241.

Vincenti W. G. (1990). What engineers know and how they know it. Balitmore and London: The John Hopkins university press. 